\title{
CONCEPTUAL INTERACTION AND SPANISH DIMINUTIVES
}

\author{
Francisco Santibáñez Sáenz \\ Universidad de La Rioja
}

\begin{abstract}
In this paper, we will treat the conceptual interaction between Spanish diminutive suffixes and lexemes from the perspective of cognitive semantics. We will review the analysis based on the ICM of size, first developed by Ruiz de Mendoza, and we will contrast its explanatory adequacy with that of other recent accounts of diminutives, such as Inchaurralde's emotional spaces and the morphopragmatic approach by Dressler \& Merlini. We will show how diminutive suffixes provide the guidelines prompting us to activate a given mental space out of our knowledge of the lexeme. This interplay is a conceptual phenomenon that takes place at the semantic level; pragmatic effects are thus mediated by semantic constraints. Finally, we shall show that diminutive categories lie at the crossroads between grammatical and lexical categories, by pointing out a similar cognitive pattern in other morphological processes, such as noun/noun compositional expressions in English.
\end{abstract}

RESUMEN:En este artículo, examinamos la interacción conceptual entre lexemas y sufijos diminutivos en español desde la perspectiva de la semántica cognitiva. Tras revisar el análisis basado en el modelo cognitivo (ICM) de tamaño, desarrollado por Ruiz de Mendoza, contrastamos su adecuación explicativa con la de otros análisis recientes de los diminutivos, como los espacios emocionales de Inchaurralde y el enfoque morfopragmático de Dressler y Merlini. Mostramos cómo los sufijos diminutivos sirven como pauta para la activación de un espacio mental dentro del conocimiento asociado al lexema. Esta interacción es un fenómeno conceptual que tiene lugar en el nivel semántico; así, los efectos pragmáticos se ven mediados por restricciones semánticas. Por último, intentamos demostrar que las categorías diminutivas se encuentran a medio camino entre las categorías gramaticales y las categorías léxicas; para ello, se señala un patrón cognitivo similar en otros procesos morfológicos, como las expresiones compuestas nombre/nombre en inglés.

\section{Introduction}

If compared with other European languages (such as English, French or German), Spanish enjoys a relatively rich and productive set of diminutive suffixes, -ito and -illo being the most frequently employed. According to traditional accounts (e.g. Alonso 1951), their use gives rise to unsystematic affective connotations, often with no apparent connection whatsoever with the denotational meaning 'small in size' (e.g. diminutives functioning as intensifiers). In this paper, we will examine some 
revealing phenomena concerning the conceptual interaction between Spanish diminutive suffixes and the lexical bases to which they are attached. We will follow and extend the cognitive approach by Ruiz de Mendoza (1996, 1997, 1998a), who has recently shown the usefulness of ICMs (Idealized Cognitive Models) in providing a systematic account of Spanish augmentative and diminutive formation ${ }^{1}$. His proposal, which is based on the exploration of the ICM of size, integrates our experiential knowledge about small and large entities together with aspects of the ICMs of control and cost/benefit. We shall discuss its explanatory power with reference to other recent accounts of diminutive suffixation, such as those offered by Inchaurralde (1997) and Dressler \& Merlini (1994). We have chosen these two accounts because, as will become evident later, they provide contrasting approaches to diminutives. Inchaurralde also attempts to deal with Spanish diminutives from a cognitive standpoint. The interest of his proposal lies in the fact that he argues for the association of spatial regions with preconceptual axiological values, which would provide a universal base for diminutives and endow his account with typological adequacy. However, his account will be shown to leave out relevant issues pertaining to the apparent lack of systematicity in assigning values to the various augmentative and diminutive suffixes. Likewise, the morphopragmatic approach proposed by Dressler \& Merlini for the study of diminutives in Italian and German (and secondarily in other languages) is problematic, since these authors assume that diminutives are almost exclusively a pragmatic phenomenon. In contrast, we shall argue that diminutives are best explained in conceptual terms and assign pragmatics the role of exploiting fairly systematic conceptual resources for communicative purposes. Thus, we shall question the necessity of a general diminutive-linked pragmatic feature, which shall lead us to argue that pragmatic effects are mediated by semantic constraints. We shall further attempt to support this view by comparing the cognitive behaviour of noun/noun compositional expressions with that of diminutive suffixes. The former are content categories, while the latter are generally considered to be grammatical. Against this, we shall argue that Spanish diminutive suffixes share many features with content categories, which places them somewhere between content and grammatical items.

\section{The ICM of size}

Studies in Spanish diminutives have often placed emphasis on their versatility (e.g. Alonso 1951; Gooch 1970; Montes Giraldo 1972). According to them,

1. According to Lakoff (1987: 68ff), knowledge is stably organized in the human mind by means of ICMs (propositional, image-schematic, metaphoric, and metonymic models); these models are complex structured wholes which may be partially activated as mental spaces for use in actual processing activities (thought, speech and understanding). 
diminutive endings usually convey subjective rather than purely denotational meanings; this accounts for their capability to combine with bases designating entities of fixed dimensions (e.g. horita: hour-DIM). It should be noted, however, that the connotative value expressed by the two basic diminutive suffixes in Spanish, -ito and -illo, tends to be quite different: -ito (regalito, 'nice little present') is often affectionate, whereas the use of -illo (regalillo, 'wretched little present') generally has a pejorative bias. Other less common yet productive suffixes include -ico and -ín, which on the whole share the positive implications of -ito, as well as -ejo ${ }^{2}$ and -uelo, more pejoratively marked than -illo itself; -ete usually involves a playful or jocular attitude $^{3}$. These values may sometimes be reversed in a seemingly arbitrary way (e.g. Estoy harto de tus bromitas, 'I'm fed up with your nasty little jokes'; Eres un granujilla, 'You're a nice little rogue').

From the point of view of cognitive semantics, Ruiz de Mendoza (1996, 1998a) has suggested that such apparent counterexamples simply obscure the fact that the behaviour of Spanish diminutives responds to quite predictable patterns. His starting point is the by now well-established idea in cognitive linguistics that knowledge is stored in our minds in the form of stable cognitive structures, called Idealized Cognitive Models or ICMs, which attempt to represent reality from a certain perspective (see Lakoff 1987, 1989). In Lakoff's view, these cognitive models are radially structured and may be extended through principles which structure other models (e.g. by means of metaphoric or metonymic extensions). Thus, according to Ruiz de Mendoza (1998a), the ICM of size -which underlies the use and interpretation of diminutives in Spanish- would incorporate into its description aspects of the ICMs of control and cost/benefit. ICMs constantly interact with one another. In this respect, Ruiz de Mendoza (1998a) points out that the many-space model of conceptual integration and its central notion of blending (see Fauconnier \& Turner 1994; Turner $\&$ Fauconnier 1995$)^{4}$ may prove useful in order to understand the complex processes

2. Lang (1992: 162) excludes - ejo from the repertoire of Spanish diminutives and prefers to classify it, together with $-u c h o$, as a pejorative suffix with a tendency to express diminutive values.

3. As is well-known, certain forms are generally associated with specific geographical varieties: -ico (Aragon, Navarre, Central America), -ín (Asturias), -iño (Galicia), -iyo (a phonetic variant of -illo characteristic of Andalusian speech), etc. In some areas of America, however, -ito has almost become generalized, and other diminutive endings have dropped out of usage. Given such a dialectal diversity, the accounts and instances of diminutive formation provided in this paper should be taken as mainly representative of its role in standard European Spanish.

4. As Turner \& Fauconnier (1995: 184) explain, "a mental space is a (relatively small) conceptual packet built up for purposes of local understanding and action. Mental spaces are constructed whenever we think and talk. They are interconnected, and they can be modified as discourse unfolds". Thus, in order to make sense of a metaphorical expression, we activate at least four mental spaces: two input spaces (source and target), a generic space (which contains structure common to both input spaces) and a blended space (which borrows partial structure from both input spaces and may as well develop emergent structure of its own). Conceptual integration takes place in the blended space. For a critical survey of some aspects of the theory, especially in its application to metaphor, see Ruiz de Mendoza (1998b). 
of cognitive interaction deriving from the combination of diminutive suffixes with lexical bases. This approach constitutes a radical departure from the reductionist views of traditional compositionality.

The different values of the Spanish diminutive are in principle associated with our experience-grounded knowledge of the way in which we usually interact with other entities according to their size. The following is the part of the propositional ICM of size which will be relevant for our discussion below (see Ruiz de Mendoza 1996: 164; 1997, 1998a):

a) Entities range in size from very small ones to very large ones.

b) A small entity is usually more manageable than a bigger one.

c) A small entity usually looks potentially less harmful than a bigger one.

A metonymic mapping allows us to extend the model by deriving corollaries (d) and (e) from (b) and (c), respectively:

d) Small entities are usually manageable; as a result, they may be perceived as likeable.

e) Small entities are usually innocuous and unimportant, and they may be easily ignored; as a result, they may be perceived as unpleasant.

The reason for the semantic distribution of the system of Spanish diminutive suffixes lies in the fact that while -ito invokes the corollary (d) of the ICM of size, which usually endows the resulting diminutive with its characteristic affectionate meaning, the frequent pejorative implications inherent in -illo derive from its association with corollary (e) ${ }^{5}$. We may refine this latter corollary by pointing out that unimportant entities, especially when they are perceived as inherently weak, may infuse the empathetic observer with feelings of pity and sorrow and, as a result, the pejorative implications are sometimes overriden by slightly affectionate overtones (e.g. chiquillo: boy-DIM, 'kid, young boy'; pobrecillo: poor-DIM, 'poor little chap'). What this refinement does is spell out in greater detail the basic logic underlying the formulation of the aforementioned corollary.

Deviations from the general pattern can be put down to formal or semantic constraints. Thus, some phonetic combinations are avoided for the sake of euphony (e.g. * sillilla: chair-DIM); on other occasions, there is a clash with homonymous lexicalized expressions (e.g. camilla: bed-DIM, 'stretcher'). According to Lázaro

5. From a functional point of view, Ruiz de Mendoza $(1996,1997)$ argues that Spanish diminutive suffixes function as attitudinal term operators which indicate some axiologically codified aspect of the speaker's relationship with the referent. He also claims the status of attitudinal term operator for the weak form of the English adjective little, except that its axiological value is expressed by other means (generally through an attributive attitudinal adjective: e.g. sweet little song/nasty little song). 
(1976), only a limited set of concrete nouns (e.g. those designating languages, placenames or the cardinal points) is reluctant to combine with diminutive suffixes; the compatibility with abstract and action nouns often depends on the endings of their lexemes.

Other apparent deviations, however, may be fully explained in terms of conceptual interaction. In this sense, the strikingly positive connotations of the diminutive granujilla are a result of the interaction in the blended space between part of the ICM of size activated by the suffix (i.e. small entities are innocuous and unimportant), and the knowledge activated by the base (and conveniently perspectivized and mitigated by the suffix) that rogues are potentially harmful people; this contrasts with the derogatory implications generally activated by -illo when added to neutral or positive bases (e.g. propinilla, 'wretched little tip'). The other problematic example listed above (Estoy harto de tus bromitas) can also be satisfactorily accounted for with reference to the ICM of size. In this case, the suffix activates corollary (d), which combines with the base to characterize its referent as an entity which is pleasant to the speaker; however, this meaning is overridden by the negative sense of the rest of the utterance and, consequently, the overall tone of complaint is reinforced by the ironic effect created in the blended space.

As we have said, the ICM of size integrates aspects of both the ICM of control and the ICM of cost/benefit. Part of the propositional model of control, as formulated by Ruiz de Mendoza (1998a, 1998b: 265), states that a person's control of an entity or set of entities may vary depending on the absence or presence of physical barriers (e.g. physical distance); we may here add that the size of an entity may also be understood as a kind of physical barrier which hinders or favours our control of that entity. Still another part of the model reflects our knowledge that maximum control of an entity is generally desirable, whereas minimum control is generally undesirable. The internal logic of the ICM of control, conveniently perspectivized by the ICM of size, allows us to draw conclusions from our impression that small entities are more manageable than large entities. The size of a small entity is not usually perceived as a significant physical barrier, so that maximum control of that entity is possible; the resulting state of affairs is then desirable. To Ruiz de Mendoza's description we want to add the observation that it is mainly the interaction between the ICM of size and relevant parts of the ICM of control that brings about the radial extension of the former model, in the sense that small entities are seen as manageable and, therefore, desirable (i.e. corollary (d) of the ICM of size).

The ICM of cost/benefit was first described by Pérez (1996) and consists basically in a reformulation in cognitive terms of the homonymous pragmatic scale provided by Leech (1983) as part of his Politeness Principle. Among other aspects, the model states that a situation which is beneficial to a beloved entity is desirable, whereas a harmful situation is undesirable. According to the internal logic of the ICM of cost/benefit, we usually make an effort to improve a state of affairs which is 
disadvantageous to beloved entities and, conversely, to maintain a favourable state of affairs. The importance of the role played by the internal logic of the ICM of cost/benefit will be illustrated in our later discussion of some of the pragmatic effects which may be associated with the use of Spanish diminutives (cf. section 3).

Now, the question is how the ICMs of control and cost-benefit interact with the ICM of size in the blended space. We argue that conceptual interaction takes place in a way which has not been analysed by Turner \& Fauconnier, since they generally point out the occurrence of interaction processes, but they fail to note what regulates the interaction. In our view, part of the ICM of size functions as a guideline for the activation of relevant supplementary knowledge from the ICMs of control and costbenefit (small entities are manageable, which is beneficial and desirable). Once they have been partly activated as mental spaces, the logical structure of the ICMs of control and cost-benefit becomes available for the language user to derive further consequences from the ICM of size. Thus, the extension process of the ICM of size would take the form of the following line of reasoning: manageable entities are beneficial and, therefore, desirable; as a result, small entities are desirable.

\section{Image-schemata and axiological principles}

Image-schemata are generic and very abstract spatial concepts which allow us to mentally structure our experiences and perceptions (see Lakoff 1987, 1989; Johnson 1987)6. An image-schematic model is made up of a set of basic structural elements arranged according to its own internal logic. For instance, the container schema mainly consists of a bounded region, a boundary and an exterior; we possess embodied knowledge that a boundary protects entities within the container from the influence of other external entities, or that if an entity A contains B, and B contains C, then A contains $\mathrm{C}^{7}$. Similarly, the path schema conjures up the recurrent pattern of an entity moving along a path, in a particular direction, from a source to a destination; we know that this movement takes place in time, and also that an obstacle across the path may prevent the moving entity from reaching its destination.

Inchaurralde (1997: 135-140) has made use of the affective value of Spanish diminutives in order to exemplify his point that space regions and spatial dimension may function as activators of emotional involvement in language. He assumes that we regard certain areas of (physical/psychological) space as our own and, as well, that we

6. In Johnson's words (1987: 29), “image schemata operate at a level of mental organization that falls between abstract propositional structures, on the one side, and particular concrete images, on the other". As a result, they are often used to make sense of more abstract concepts (e.g. functioning as generic spaces in metaphoric mappings; see Ruiz de Mendoza 1998c).

7. See Peña (1997ab) for further development of the internal logic of the container image-schema. 
tend to increase the size of our personal spaces as much as possible. Axiologically, what belongs to one's space is perceived as good; other areas of space are placed somewhere along the good/bad continuum. His proposal is partly based on Krzeszowski (1993), who argues that image-schemata incorporate preconceptual axiological values into their internal structure (e.g. in the part-whole schema, WHOLE is perceived as positive, whereas PART, which is associated with the experience of fragmentation, is negative). The axiological poles of image-schemata, in turn, would give rise to basic axiological concepts, such as good/bad, true/false, etc. Inchaurralde (1997: 138-139) analyses the non-denotational use of Spanish diminutives with relation to the emotional proximity between the speaker and the object: "we feel close to the entity affected by it and for that reason we make it enter our personal space by reducing its dimensions" (what he calls the "diminutive" effect). In contrast, the augmentative involves an increase in size of the entity (the "augmentative" effect), which is perceived as a potential threat to our personal space 8 .

Let us discuss now the extent to which this proposal is consistent with the previous account of Spanish diminutives in terms of idealized cognitive models. It is possible to recognize some similarities between Inchaurralde's "diminutive" effect and corollary (d) of the ICM of size, according to which small entities, being usually manageable, may be perceived as likeable. In fact, Ruiz de Mendoza (1998a) mentions in passing that the structure and logic of both the container schema and the path schema play a central role in the description of the ICM of control; thus, control over a given entity may be hindered or even prevented by the distance along a path or by the boundaries of a container. Inchaurralde (1997: 135) understands emotional involvement in terms of affective proximity or detachment; when the psychological distance is reduced between the speaker and the external entity, the latter may more easily gain access to the former's personal space. Similarly, that personal space may be experienced as a container whose boundaries it is in our power to keep closed or, alternatively, to open up so that other entities, as long as they are small enough, may move from the exterior to the interior of the container.

However, the model offered by Inchaurralde is not satisfactory on its own. At least in this rather sketchy version, it fails to account for those frequent occasions in Spanish when the diminutive (prototypically -illo) is used derogatorily and, conversely, the augmentative presents overtly positive connotations (e.g. estilazo, 'terrific style, elegance'; cochazo, 'smashing car'; peliculón, 'superb film'). Inchaurralde (1997: 140) provides a rather ad hoc explanation for the problematic example padrazo (father-AUG;' loving father', but often also 'over-indulgent father'). The positive connotations of this augmentative expression are associated with an

8. In a similar vein, Gooch (1970: 3) finds psychological motivation for the use of diminutive suffixes in our "fear of things that are big and a concomitant desire to reduce them to friendly proportions", which are for us "emotionally manageable" (italics in the original). 
increase in the parenthood space, which allows other entities to gain access to it. Augmentatives are better accounted for with relation to corollaries ( $f$ ) and ( $g$ ) of the ICM of size (see Ruiz de Mendoza 1998a):

(f) Large entities are hardly manageable and may look disproportionate, so they may be perceived as unpleasant.

(g) Large entities are important and even majestic, so they may be perceived as likeable.

Taylor (1989: 86) structures the radial category 'father' according to five domains ("models" in Lakoff's terminology): the genetic domain, the responsibility domain, the authority domain, the genealogical domain and the marital domain. Since no domain in Taylor's description explicitly includes the idea of paternal love, we argue for the need of a sixth structuring domain, both in English and in Spanish, which we call the "protection" domain ("The father loves the child and tries to protect him/her against any potential harm"); this would be, broadly speaking, the counterpart of the nurturance model for 'mother' in Lakoff (1987: 74). Thus, the positive meaning of padrazo ('loving father') derives from the corollary (g) of the ICM of size, which serves as a guideline to activate the protection domain within the category. Conversely, its possible pejorative connotations are related to the corollary (f), which allows us to activate the same domain; now, paternal love is perceived as excessive and disproportionate, which comes into conflict with the converging authority domain ("The father is a figure of authority, responsible for the discipline of the child").

The diminutive suffix -illo is capable of conveying negative implications because, as explained above, it activates the corollary (e) of the ICM of size, according to which small entities may be easily ignored and, consequently, they may stand for something unpleasant. The so-called "diminutive" effect would not apply on such occasions, since it would not be judicious to attempt to increase the size of one's mental space with entities of insignificant dimensions, characterized by their lack of value. In this respect, a further problem with Inchaurralde's model is related to his axiological claim that we feel all the possessions (entities and areas) located within our personal space and accepted by us as good, which does not hold true according to our everyday experience; we may manage to detach ourselves from certain hostile forces but, in a way, we are constantly forced to accept unpleasant intruders (ranging from a fever to VAT). This problematic issue may be traced back to Krzeszowski (1993: 314-317), who argues that, according to the basic bodily experiences underlying the body-as-a-container schema (breathing, eating, excretion), the orientation 'into' is axiologically characterized as positive, whereas the orientation 'out' is associated with negative values. Apart from the obvious objection that we may eat poisonous toadstools and breathe in polluted air, it should be noted that some highly unpleasant experiences, such as disease and negative emotions, are usually 
perceived as going on within our body (consider certain metaphorical expressions based on the container schema, e.g. to be full of rage or to have butterflies in one's stomach).

Although a proper theoretical background linking spatial notions and axiological principles may be useful to account for some aspects of the behaviour of Spanish diminutives, we should argue that Inchaurralde's proposal is in need of further refinement. At its present stage, it fails to enjoy the cognitive validity and explanatory power of the ICM of size, with which it is only partially consistent.

\section{The morphopragmatic approach}

Dressler \& Merlini (1994) have proposed a morphopragmatic approach to the study of traditional morphological categories; in contrast with other strictly modular models, they are particularly interested in the general pragmatic effects of morphological operations. Their exhaustive analysis of diminutive formation is mainly based on Italian and German data, but they explicitly aspire to extend their conclusions to other languages (1994: 394-400) (in fact, their book includes occasional examples in Spanish). Their basic claim is that diminutive suffixes possess the pragmatic meaning feature [non-serious] which is applied to -and therefore modifies- the speech act or speech situation as a whole rather than to the meaning of a specific lexical base. The feature [non-serious] is regarded as integrating the more general pragmatic feature [fictive] with the semantic feature [non-important], an alloseme of [small] (often totally replaced by the central pragmatic feature). Fictiveness involves a temporary shift from usual "real-world" standards according to the speaker's specific evaluation; this would subsidiarily account for the occurrence of subjectivity in speech acts/situations containing diminutive forms. They oppose their analysis (based on a so-called maximalist hypothesis) to the minimalist view, which claims that the pragmatic dimension of diminutives is derived from the application of general pragmatic principles to their semantic features [small] and [non-serious]. It should be argued, however, that this opposition responds to a narrow concept of the semantic discipline. The encyclopaedic nature of cognitive semantics provides, as will become evident, more adequate comparative tools to test the validity of a morphopragmatic analysis of diminutive suffixation.

Thus, as noted before, the cognitive behaviour of Spanish diminutives can be traced back to our experiential and motor knowledge that objects are perceived as having different sizes, and that we tend to interact differently with them according to such perceptions and to additional information retrievable from the control and cost/benefit ICMs. One possible objection which may be raised to the explanatory relevance of such pragmatic features as [fictive] and [non-serious] is that, unlike what happens with the ICM of size, it is not clear what sort of effect they have on the lexical item to which the 
diminutive suffix is applied. In Dressler \& Merlini's account, the two pragmatic features seem to operate exclusively from the suffix to the utterance. However, it is evident from our previous analysis that, before the diminutive suffix may affect the whole expression, there must be a conceptual interaction between the base and the suffix.

Consider the following example in Italian provided by Dressler \& Merlini (1994:157-8):

Come vorrei essere nel mio lettino!

how I would like to be in my bed-DIM

'How I wish I were in my nice comfy bed!'

(Spanish: ;Cómo me gustaría estar en mi camita!)

According to these two authors, here "the diminutive contributes [...] to conveying the impression that the speaker is not serious about going to bed". This would contrast with Come vorrei essere nel mio letto! (with the plain lexeme), which is in principle interpreted as an actual wish to be in bed. In semantic terms, however, the example with the diminutive expression also expresses a desire to be in bed; in addition, the diminutive reflects a positive evaluation of the bed as (probably) comfortable, providing relief, etc., that is, by invoking the corollary (d) of the ICM of size $^{9}$, the diminutive highlights those features of letto which, according to our worldknowledge, are likeable (beds are usually comfortable, provide relief, etc.). Our account does not deny that, probably, this sort of expression does convey in Italian the impression that the speaker is not really serious about its semantic content. The effect is also possible in English and Spanish, but in these languages there is a less conventionalized association of the expression with the 'non-serious' value. Thus, the true problem with Dressler \& Merlini's description is that it is not truly typological (for example, it fails to carry over to other languages, such as English or Spanish).

Now, the question is how we can arrive at the 'non-serious' value. We argue that the answer is not to be found in an overall pragmatic feature, but rather in implicature strategies. Here, the well-known Principle of Relevance ${ }^{10}$ may be useful, together

9. The Italian language also enjoys a relatively rich paradigm of diminutive suffixes, -ino being the most frequent one. According to the data provided by Dressler \& Merlini, it is not possible to ascertain whether the ICM of size is reflected in standard Italian by clearly codified distinctions such as -ito/-illo in Spanish. Nevertheless, they point out some axiological specializations of the pair -ino/-etto: donnetta (woman-DIM; pejorative)/donnina (woman-DIM; more neutral); braccette (arms-DIM; pejorative when applied to men)/braccine (arms-DIM; generally positive) (Dressler \& Merlini 1994: 166).

10. The Principle of Relevance, as formulated by Sperber \& Wilson (1986: 158), states that "every act of ostensive communication communicates the presumption of its own optimal relevance". Relevance is mainly conceived as the adequate balance between the contextual effects yielded by a given utterance and the processing effort involved in that process: "other things being equal, an assumption with greater contextual effects is more relevant; and, other things being equal, an assumption requiring a smaller processing effort is more relevant" (Sperber \& Wilson 1986: 125). 
with an understanding of how conventionalization processes work. Come vorrei essere nel mio lettino! expresses a desire to be in bed since the bed is likeable; if we have a context in which both speaker and addressee know that the speaker cannot really go to bed, or that he needs some rest but not necessarily in his bed, the relevance of the utterance would only be achieved if the speaker is taken to be speaking nonseriously. What is characteristic of the Italian language is that employing such a construction (an expression of desire including a diminutive) in order to convey the idea of non-serious speech has become, in Morgan's terminology (1978), a "convention of usage", in the same way as it is conventional in English to use a question of the kind Can you pass me the salt? in order to make a request. Although the construction preserves its semantic content, it is possible to derive the intended implicature in a fairly automatic way. The conventionalization process has not taken place, at least to the same degree, in languages such as English or Spanish, so that it is necessary for the addressee to actively infer the implicated value of non-seriousness from both the literal meaning of the expression and additional contextual information.

We have seen, from the perspective of cognitive semantics, that the process of conceptual interaction is first carried out between the two members of a diminutive expression; the suffix evokes a part of the ICM of size which, in turn, leads us to activate a given domain within our encyclopaedic knowledge of the lexeme. In Dressler \& Merlini's morphopragmatic approach, however, the base to which a diminutive suffix is added is simply regarded as a landing-site of the pragmatic feature [non-serious]; this would account for the fact that, in some languages (including Spanish and Italian), it is possible to attach diminutive suffixes to other grammatical categories different from the noun, such as adjectives, verbs and adverbs. But our model also offers a satisfactory explanation for such non-prototypical instances of diminutivization. For instance, let us consider the following evaluative utterance (Dressler \& Merlini 1994: 155):

\author{
Maria è grassina. \\ Mary is fat-DIM \\ 'Mary is rather plump.' \\ (Spanish: María está gordita.)
}

This is analysed from the morphopragmatic standpoint as a clear example of the modified standards which are associated with the so-called fictive approach. It is certainly true that the use of a diminutive here somehow blurs the evaluative load, but this should be understood as a side effect of the cognitive interaction between the mental spaces activated by the suffix and the lexeme. Thus, the corollary (d) of the ICM of size perspectivizes our knowledge of fatness as a property generally taken to be negative by presenting it in a more favourable, likeable light (perhaps the speaker 
knows that Mary is a friend of the addressee's, or either the speaker or the addressee is fat him/herself).

It should be noted that, by pointing out some of the potential inadequacies in the explanatory power of the morphopragmatic approach, we do not in the least mean that diminutives cannot be exploited for pragmatic purposes. What is implied is rather that pragmatic effects derive from general semantic and pragmatic principles applied to the semantic value of the diminutive expression when it interacts with other parts of the textual unit or with certain aspects of the speech situation (e.g. difference in status between speaker and addressee, degree of formality, etc.). The oversimplification inherent in the morphopragmatic approach will become more evident in the light of the following example:

(1) ¿Me haces un favorcito? ('Can you do me a nice little favour?')

(2) ¿Me haces un favorcillo? ('Can you do me just a little favour?')

These two utterances are quite representative of the use of Spanish diminutives in mitigated requests. From a morphopragmatic point of view, the modification of the illocutionary point of the request would be put down, in both examples, to the application of the general pragmatic feature [non-serious] to the utterance as a whole. Such an account, however, would completely ignore the fact that the same pragmatic effect is achieved by characterizing the required action as likeable, in (1), and as unimportant, in (2). In this pair of examples we can see the role played by the ICM of cost/benefit in extending the internal structure of the ICM of size. In (1), the suffix -ito presents the favour as a beneficial action to the speaker by activating the corollary (d) of the ICM of size and, as a result, the addressee should make an effort to please him/her and do the favour; in (2), conversely, the suffix -illo places emphasis on the reduced effort involved in the favour, so it is understood that the addressee should please the speaker because doing the favour would bring about no significant cost to him/her.

\section{Similarities to compositional morphology}

In the previous sections, we have postulated that diminutive suffixes function as cues which prompt us to activate a mental space out of our propositional knowledge about the entity expressed by the lexical base; as a result of this interplay, the diminutive is semantically characterized as a meaningful whole which, in turn, may relate to the other lexical elements forming part of a specific utterance as well as to the speech situation where that utterance occurs. Pragmatic effects may thus be obtained by means of implicature, often strong enough to override the meaning of the isolated diminutive. By way of illustration, in perrito ('nice little dog'), the choice of -ito, 
which is associated with the corollary (d) of the ICM of size, leads us to focus on those attributes of dogs capable of making them likeable entities (e.g. those underlying the metaphorical expression man's best friend) rather than unpleasant or harmful entities (e.g. the well-known fact that dogs guarding buildings may bite trespassers, which would account for the oddity of a written warning such as ? Cuidado con el perrito! ('Beware of the nice little dog!')). But that very same warning may well be reinterpreted as blatantly ironic if uttered in front of a fierce large dog, when it is obvious to both speaker and hearer that the speaker is not being truthful on purpose ${ }^{11}$. Note, however, that this perspectivizing effect is not usually generated in the opposite direction (from the lexical base perro to the diminutive suffix -ito). Our concern here is mainly to show that such a pattern of conceptual interaction can also be recognized in other morphological phenomena. With this view in mind, we will analyse the cognitive mechanisms underlying some instances of expansion through noun/noun compound formation in English ${ }^{12}$.

First, let us start our discussion by considering a fully lexicalized compositional form, such as raincoat. In contemporary Western cultures, we all possess relatively wide experiential knowledge of such entities as coats and rain; this knowledge is stored in our long-term memory and can be expressed by means of complete propositions. For instance, we know that coats are garments that we sometimes wear over other clothes to protect us from bad weather, and that rain is made up of small drops of water which fall from the sky when it is cloudy; in addition, we have probably been taught that rain is produced as a result of the condensation of water vapour in the atmosphere, that it is essential for human survival, that it allows crops to grow, or that in some areas of the world (e.g. jungles) it rains more often than in others (e.g. deserts). Obviously, we also know a lot about raincoats (we wear them when it rains, they are made of waterproof materials, etc.); however, since this knowledge is associated with the referent rather than with the semantic characterization of the individual items in the compound, it will be irrelevant for our discussion. Our goal here is simply to analyse how we produce and understand compositional forms out of the semantic properties of their constituents rather than the conventionalized connection between the expression and the referent. Under those circumstances, we can observe that one of the members of the compound (here the base coat, which conveys the idea of protection from bad weather) provides the necessary instructions to activate a relevant domain cut off from the rest of our encyclopaedic knowledge

11. This would be explained by Griceans as a flouting of one of the maxims of Quality (see Grice 1975).

12. Marchand (1969: 11) defines expansion as "a combination AB in which B is a free morpheme (word) and which is analysable on the basis of the formula $\mathrm{AB}=\mathrm{B}$. This means that $\mathrm{AB}$ belongs to the same word class and lexical class to which B belongs". He goes on to distinguish between compounds (steamboat, colorblind) and prefixed words (rewrite). 
about rain: we are aware that rain makes both us and our clothes wet; this is generally an unsatisfactory state of affairs (e.g. we may get a cold), so it is logical that we try to find out ways of preventing it from materialising (a coat may protect us from rain). The fact that rain is beneficial for crops, for example, is totally irrelevant in the present scenario. Conversely, the nominal modifier simply reduces the potential denotation of the base of the compound, that is, it helps us to select a set of potential referents of the lexical expression raincoat from all possible coats; however, at least at a first stage, it fails to perspectivize our encyclopaedic knowledge about coats for the purpose of conceptual interaction in the blended space.

A similar cognitive process is felt to underlie the compound rain gauge. We know that a gauge is a device that measures the size or amount of something; it is this second member of the compound that serves as a sort of guideline to activate the specific domain within our knowledge of rain which characterizes it as a physical entity that can be measured. We may also know that those measurements may be of interest to meteorologists, the people who study weather conditions. The fact that we get wet when it rains is not relevant here. Again, it should be observed that the function of the nominal modifier rain is only to diminish the range of applicability of the base.

The kind of analysis proposed here may sound paradoxical, since it is quite different from the traditional view of what a modifier/head relationship should be like. Likewise, it also seems to partly contradict the findings of attribute listing experiments such as those described in Ungerer \& Schmid (1996: 88-95). According to these authors, the attribute listings provided by their informants for the categories RAIN, COAT and RAINCOAT show that the last one shares more attributes with the modifier category (association with wetness, water, thunderstorms, etc.) than with the head category (shape, material, etc.). However, it should be noted that their approach, which is mainly concerned with the relationships between different levels of categorization, incorporates into the process of conceptual integration an additional input space, the one activated by our knowledge of the referent of the compound ${ }^{13}$. Our proposal attempts to focus on the cognitive interaction between the members of compositional expressions, but, as we have seen, the process is significantly obscured when these expressions become fully lexicalized, often with modified stress (the cases of both raincoat and rain gauge, and many others such as wheelchair, beehive, birdcage, etc.).

13. Ungerer \& Schmid (1996: 89-90) distinguish the following attributes for the subordinate category APPLE JUICE: a salient specific attribute ('made from apples'), attributes borrowed from JUICE ('liquid', 'no alcohol', etc.), attributes borrowed from APPLE ('yellow or similar colour', 'fruity', etc.), attributes borrowed from both JUICE and APPLE ('healthy', 'tastes good') and non-derived attributes ('mixed with soda water', 'naturally cloudy'). These "non-derived" attributes, however, stem from our general knowledge about apple juice (how we interact with it, the way it looks like, etc.) (cf. Ruiz de Mendoza 1998b, esp. his criticism of the claim by Turner \& Fauconnier (1995) that blends may develop emergent structure of their own independently of input spaces). 
For a better understanding of the similarities between compound and diminutive formation, it may be useful to analyse compositional forms with a lower degree of lexicalization ${ }^{14}$. When the denotation of a compositional expression is not conventionally assigned to the expression as a whole but rather depends on the interaction of its constituent parts (and, therefore, the expression is not "listed" as an independent entry in our mental lexicon), it is easier to examine the cognitive nature of that interaction and, most interestingly, its dynamic relationship with the specific speech act or situation where it occurs. Consider, thus, the compound concrete factory (unlexicalized, to my knowledge) regardless of any possible context of utterance. Among other things, we know that factories are buildings where goods are produced in large quantities, generally with the use of machines. On the other hand, we know, in more or less detail, that concrete is a very hard building material which is made by mixing together sand, cement, small stones and water. Within the internal radial structure of the category FACTORY, some cognitive models (e.g. goods are made in factories) seem to be more central than others (e.g. factories are buildings); this accounts for the fact that, in an unmarked context, we would probably expect this compositional expression to mean 'a factory where concrete is made', which necessarily involves activating our knowledge of concrete as a manufactured product rather than as a building material. Our expectations, however, may be cancelled out by the rest of the utterance (e.g. They make furniture in the concrete factory over there) and/or by the speech situation (e.g. if it is shared knowledge that the factory is made of concrete, or if the utterance is produced in front of a factory visibly made of concrete). The reinterpretation of the compound is then carried out according to general semantic and pragmatic principles, with no need to attach a specific pragmatic rule to English compositional morphology. Similarly, it is not necessary to invoke the application of an all-embracing morphopragmatic feature [non-serious] to account for the ironic use of ;Cuidado con el perrito!, as pointed out at the beginning of this section.

It may be aptly argued that the possibilities of cognitive interaction are much more restricted with grammatically codified diminutive suffixes (-ito and -illo each being prototypically associated with a specific part of the ICM of size) than with lexical compound members, which are linked to more complex cognitive categories (often clusters of cognitive models radially structured). Nonetheless, we have shown here how, on the whole, the cognitive setup of Spanish diminutives and unlexicalized English compositional forms is established in virtually the same manner. The fact that

14. A large number of Spanish diminutives has also undergone processes of heavy lexicalization: e.g. cochecito (car-DIM, 'pram'), bocadillo (bite-DIM, 'sandwich'), pasillo (step-DIM, 'corridor'), barbilla (beard-DIM, 'chin'), sombrilla (shadow-DIM, 'sunshade'), etc. The predominance of -illo over -ito in lexicalized forms is usually put down to its higher frequency in former times. See Gooch (1970) for further examples of diminutive expressions with changed or specialized meanings, and Náñez (1973) for an informative diachronic study of Spanish diminutives chiefly based on literary texts. 
-ito and -illo invoke ICMs or parts of ICMs leads us to question the rigidity of the traditional opposition between grammatical and lexical categories, at least as far as their cognitive status is concerned.

\section{Conclusion}

In this paper, we have carried out a brief survey of the insights which cognitive semantics may offer into the nature and behaviour of Spanish diminutives. We have tested the cognitive adequacy and explanatory power of an account based on the ICM of size by comparing and contrasting it with other alternative proposals, such as Inchaurralde's emotional spaces and the morphopragmatic approach by Dressler\&Merlini. We have seen how diminutive suffixes function as cues which guide our activation of mental spaces within our propositional knowledge of the root word. This is a process of cognitive interaction that takes place at the semantic level; pragmatic effects may be derived according to semantic constraints and general pragmatic principles of a Gricean kind. Finally, we have tentatively proposed that the overall cognitive setup of synthetic diminutives may be recognized in other patterns of word formation, such as unlexicalized compositional expressions in English; this is particularly significant inasmuch as diminutive suffixes seem to bridge the gap between grammatical and lexical categories.

\section{References}

Alonso, Amado. 1951. "Noción, emoción, acción y fantasía en los diminutivos". In Estudios Lingüísticos: Temas Españoles, 195-229. Madrid: Gredos.

Dressler, Wolfgang U. \& Lavinia MERLINI BARBARESI. 1994. Morphopragmatics. Diminutives and Intensifiers in Italian, German, and Other Languages. Berlin/New York: Mouton de Gruyter.

FAUCONnIER, Gilles \& Mark Turner. 1994. "Conceptual projection and middle spaces". La Jolla, Department of Cognitive Science, University of California, San Diego. (Internet document available from http://cogsci.uscd.edu).

Gooch, Anthony. 1970. Diminutive, Augmentative and Pejorative Suffixes in Modern Spanish. A Guide to their Use and Meaning, 2nd ed., Oxford: Pergamon Press.

Grice, H. Paul. 1975. "Logic and Conversation”. In P. Cole \& J.L. Morgan, eds., Syntax and Semantics Volume 3: Speech Acts, 41-58. New York: Academic Press.

INCHAURRALDE, Carlos. 1997. "Space, reference, and emotional involvement". In S. Niemeier \& R. Dirven, eds., The Language of Emotions. Conceptualization, expression, and theoretical foundation, 135-154. Amsterdam/Philadelphia: John Benjamins. 
Johnson, Mark. 1987. The Body in the Mind. The Bodily Basis of Meaning. Imagination and Reason. Chicago: University of Chicago Press.

KRZESKOWSKI, Tomasz. 1993. "The axiological parameter in preconceptual image schemata", in R.Geiger \& B.Rudzka-Ostyn, eds., Conceptualizations and Mental Processing in Language. Cognitive Linguistics Research 3, 307-329. Berlin: Mouton de Gruyter.

LAKofF, George. 1987. Women, Fire, and Dangerous Things: What Categories Reveal About the Mind. Chicago: University of Chicago Press.

LAKOFF, George. 1989. "Some empirical results about the nature of concepts". Mind \& Language 4: 103-129.

LANG, Mervyn F. 1992. Formación de Palabras en Español. Morfología Derivativa Productiva en el Léxico Moderno. Madrid: Cátedra.

LÁzaro Mora, Fernando A. 1976. "Compatibilidad entre lexemas nominales y sufijos diminutivos". Boletín Instituto Caro el Cuervo XXXI: 41-57.

LEECH, Geoffrey. 1983. The Principles of Pragmatics. London/New York: Longman.

Marchand, Hans. 1969. The Categories and Types of Present-Day English WordFormation. A Synchronic-Diachronic Approach, 2nd ed. Munich: C.H. Beck'sche Verlagsbuchhandlung.

Montes Giraldo, José Joaquín. 1972. "Funciones del diminutivo en español: ensayo de clasificación”. Boletín Instituto Caro el Cuervo XXVII: 71-88.

Morgan, J.L. 1978. "Two Types of Convention in Indirect Speech Acts". In P. Cole, ed., Syntax and Semantics Volume 9: Pragmatics, 261-280. New York: Academic Press.

NÁÑEz FERnÁndez, Emilio. 1973. El diminutivo. Historia y funciones en el español clásico y moderno. Madrid: Gredos.

PEÑA CERVEl, María Sandra. 1997a. "The role of the event structure metaphor and of image-schematic structure in metaphor for happiness and sadness". Miscelánea. A Journal of English and American Studies, 18: 253-266. Universidad de Zaragoza. Servicio de Publicaciones.

PeÑa Cervel, María Sandra. 1997b. "The container image-schema and other subsidiary image-schemata". In Actas del XXI Congreso AEDEAN. Universidad de Sevilla, in press.

PÉREZ HERnÁNDEZ, Lorena. 1996. "The cognition of requests”. Estudios Ingleses de la Universidad Complutense 4:189-208. Servicio de Publicaciones UCM, Madrid.

RuIZ DE MENDOZA IBÁÑEZ, Francisco J. 1996. "Some notes on the grammatical status of the Spanish -ito/-illo diminutives and their translation into English". Pragmalingüística 3-4 (1995-1996):155-172. Universidad de Cádiz.

RuIZ de Mendoza IBÁÑEZ, Francisco J. 1997. "Morfología flexiva y derivativa en la gramática léxico-funcional; el caso de la sufijación apreciativa”. In M.J.Feu Guijarro \& S.Molina Plaza, eds., Estudios sobre el léxico: el enfoque lexemático- 
funcional. Servicio de Publicaciones de la Universidad de Castilla La Mancha. Colección Escuelas de Traductores de Toledo, in press.

Ruiz de Mendoza IbÁÑEZ, Francisco J. 1998a. "El modelo cognitivo idealizado de 'tamaño' y la formación de aumentativos y diminutivos en español”. In R.Maldonado, ed., Estudios Cognoscitivos del Español I. México: Instituto de Investigaciones Filológicas UNAM, in press.

Ruiz de Mendoza IbÁÑez, Francisco J. 1998b. "On the nature of blending as a cognitive phenomenon". Journal of Pragmatics 30: 259-274. North-Holland: Amsterdam.

Ruiz DE MENDOZA IBÁÑEZ, Francisco J. 1998c. "Metaphor, metonymy and conceptual interaction". Atlantis, in press.

SPerber, Dan \& Deirdre Wilson. 1986. Relevance. Communication and Cognition. Oxford: Basil Blackwell (2nd ed. 1995).

TAYLOR, John R. 1989. Linguistic Categorization. Prototypes in Linguistic Theory. Oxford: Clarendon (2nd ed. 1995).

TURnER, Mark \& Gilles FaUCONNIER. 1995. "Conceptual integration and formal expression". Metaphor and Symbolic Activity 10: 183-204.

Ungerer, Friedrich \& Hans-Jörg SCHMID. 1996. An Introduction to Cognitive Linguistics. London/New York: Longman. 